\title{
Postura epistêmica e parafraseabilidade diferencial em condicionais ${ }^{1}$
}

\author{
Epistemic stance and differential paraphrasability in \\ conditionals
}

\section{Gilberto Gomes UENF \\ Priscila Mattos Monken UENF}

\section{Resumo}

O objetivo deste trabalho é estudar a postura epistêmica positiva ou neutra em condicionais, a partir do julgamento da aceitabilidade diferencial de paráfrases de se com já que ou caso, respectivamente. Após breve discussão da possibilidade da postura epistêmica positiva em condicionais, é relatada pesquisa empírica, em que frases condicionais foram apresentadas em três contextos: 1. contexto indefinido (frase isolada); 2 . contexto indutor de certeza; 3. contexto indutor de incerteza. A escolha das paráfrases correlacionou-se com a atribuição induzida de certeza ou incerteza e, no contexto indefinido, ambas as paráfrases mostraram-se igualmente possíveis, de acordo com o contexto imaginado pelo sujeito. A parafraseabilidade diferencial mostrou-se um recurso metodológico útil. Confirmou-se a possibilidade de postura epistêmica positiva em condicionais.

\section{Palavras-chave}

Condicionais, Postura epistêmica, Parafraseabilidade diferencial, Condicionais factuais. 


\section{Abstract}

The aim of this article is to study positive or neutral epistemic stance in conditionals through the differential acceptability of paraphrases of se (if) with já que (since) or caso (in case), respectively. After a brief discussion of the possibility of positive epistemic stance in conditionals, an empirical research project is related, in which conditional sentences were presented in three contexts: (1) indefinite context (isolated sentence); (2) certaintyinducing context; and (3) uncertainty-inducing context. Choice of paraphrases was correlated to the induced attribution of certainty or uncertainty and, in the indefinite context, both paraphrases were showed to be equally possible, in accordance with the context imagined by the subject. Differential paraphrasability was showed to be a useful methodological tool. The possibility of positive epistemic stance in conditionals was confirmed.

\section{Keywords}

Conditionals, Epistemic stance, Differential paraphrasability, Factual conditionals. 


\section{Introdução}

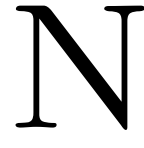

uma frase condicional da forma $S e A$, (então) $B$, chamamos $A$ (a oração subordinada condicional sem a conjunção $s e$ ) de antecedente (ou prótase) e $B$ (a oração principal, sem a palavra então, caso presente) de consequente (ou apódose). Koch (2000, p. 129) observa que uma frase condicional não afirma que o antecedente é verdadeiro; todavia, se o antecedente for verdadeiro, o consequente também o será. O objetivo da enunciação de uma frase condicional, assim, não é a asserção do antecedente, nem do consequente, mas da relação condicional entre ambos. Entretanto, pode-se verificar que, embora normalmente uma frase condicional não afirme a verdade do antecedente, em certos casos ela pode fazê-lo:

(1) Se ele fez o que fez, merece punição.

Nesse caso, parece óbvio que o falante acredita na verdade do antecedente, ou pelo menos está falando como se nela acreditasse. Comparemos essa frase com: (2) Se ele fez o que dizem que ele fez, merece punição.

Nesta, o falante apenas supõe que o indivíduo de quem fala tenha feito aquilo que dizem que ele fez. Na primeira, entretanto, não são os outros, mas sim o próprio falante quem diz que ele o fez. Seu antecedente, portanto, não tem o objetivo de fazer uma suposição, mas sim de estabelecer uma premissa, a partir da qual decorre a conclusão enunciada pelo consequente. $\mathrm{O}$ falante aceita a verdade do antecedente. Note-se que a segunda frase pode ser parafraseada com o futuro perfeito do subjuntivo, mas não a primeira:

(3) Se ele tiver feito o que você diz que ele fez, merece punição.

Ao contrário, não caberia dizer:

(4) *Se ele tiver feito o que fez, merece punição. 
Leão (1961, p. 31-32) distingue três tipos de frases condicionais, que ela chama de períodos hipotéticos, a saber, período hipotético do real, período hipotético do potencial e período hipotético do irreal. No realis "a condição é, foi ou deve ser realizada efetivamente; trata-se de um fato cuja realidade se reconhece; às vezes é uma realidade que se deseja acentuar". A autora observa que esse período é caracterizado pelo fato de apresentar verbos no modo indicativo. No período hipotético do potencial, "a condição é eventual, simplesmente possível. O fato pode realizar-se ou não, mas não há nenhum pronunciamento do falante sobre a realidade desse fato". Já o irrealis é expresso por uma "condição contrária à realidade". Isto é, não pôde e nem nunca poderá realizar-se.

Outros autores, como Costa (1997, p. 27), incluem os casos de incerteza quanto à realidade do antecedente dentro do irrealis. Outros ainda, como Taylor (1997), chamam esses casos de condicionais hipotéticas. Vemos, assim, que não há uniformidade no uso da nomenclatura. Segundo o último autor, num condicional factual, presume-se que o conteúdo do antecedente seja verdadeiro, enquanto, num contrafactual, esse conteúdo é tido como contrário aos fatos. Entre essas duas categorias, acrescenta, ficam as condicionais hipotéticas, nas quais o conteúdo do antecedente é considerado como uma possibilidade, nem de acordo com a realidade, nem necessariamente inconsistente com ela (TAYLOR, 1997, p. 301).

Fillmore (1990, p. 142) usa o conceito de postura epistêmica, segundo o qual o falante pode ter três relações epistêmicas com o mundo representado pela condicional: a) ele pode considerá-lo como o mundo real; b) pode considerá-lo como distinto do mundo real; c) pode não saber se ele é o mundo real ou não. Essas três posturas epistêmicas são chamadas, respectivamente, de positiva, negativa e neutra.

Certos autores, como Harder (1996), tendem a não reconhecer a possibilidade das condicionais com postura epistêmica positiva. Dancygier e Sweetser $(2000 ; 2005)$ notam que a postura epistêmica positiva está preferencialmente associada, em inglês, às conjunçōes when, since e because (que correspondem em português a quando, já que e porque). Tendem, assim, a ver a incerteza ou irrealidade como algo inerente à natureza das frases condicionais, buscando uma explicação especial para os casos que parecem contrariar essa norma.

No polo oposto, Schwenter (1999, p. 4 e 40) combate a tese de que as condicionais sempre envolvam uma postura epistêmica neutra ou negativa. 
Segundo ele, a condição hipotética não é parte da semântica codificada dos marcadores condicionais, mas é dada pragmaticamente, por meio de uma implicatura conversacional generalizada, que pode ser cancelada.

Gomes (2008) sustenta também a realidade das condicionais factuais, propondo uma nova nomenclatura para dois dos três tipos: em contraste com as condicionais tradicionalmente chamadas de contrafactuais (counterfactual conditionals), distingue as accepted-fact conditionals (condicionais de fato aceito) e as uncertain-fact conditionals (condicionais de fato incerto). Destaca também a distinção de tempos verbais de que o português dispõe para os dois últimos tipos, sendo o futuro do subjuntivo exclusivo das condicionais de fato incerto e os tempos do indicativo necessários para as de fato aceito. Gomes (2008) salienta ainda a possibilidade de paráfrase de se (em inglês, if) com caso (in case), exclusivamente nas condicionais de fato incerto e nas contrafactuais, e com $j a ́$ que (since), exclusivamente nas de fato aceito.

São os seguintes os principais pontos defendidos por Gomes (2008): as condicionais factuais (ou de fato aceito) com se podem ser parafraseadas com $j a ́$ que, mas não com caso; já as condicionais hipotéticas (ou de fato incerto) - assim como as contrafactuais - com se podem ser parafraseadas com caso, mas não com já que. A interpretação de uma condicional com o futuro do subjuntivo no antecedente é necessariamente de fato incerto. A interpretação de uma condicional com um tempo do indicativo no antecedente pode ser de fato aceito ou de fato incerto. Entretanto, para certos dialetos da língua portuguesa, o uso do indicativo no antecedente, em certos casos, favorece a interpretação de fato aceito, já que, nos casos de fato incerto, esses dialetos usam, preferencialmente, nesses casos, o futuro do subjuntivo.

A pesquisa empírica da qual relatamos aqui uma parte integrou a dissertação de um dos autores do presente artigo, orientada pelo outro. $\mathrm{O}$ presente trabalho tem como objetivo investigar a postura epistêmica positiva ou neutra, em condicionais com tempos do indicativo na prótase, através da aceitabilidade diferencial de paráfrases com já que e caso, respectivamente. Investigamos o papel da postura epistêmica atribuída ao falante na aceitação pelo sujeito dessas paráfrases.

Tendo em vista que vamos estudar paráfrases de se com caso e com já que, é pertinente a observação gramatical de Neves (2000, p. 848), de que se admite formas verbais tanto do indicativo quanto do subjuntivo, enquanto caso, assim 
como outras conjunções condicionais, ocorre só com o subjuntivo, e já que, exclusivamente com o indicativo. Este sendo o modo do realis, torna-se lógica a associação dessa locução conjuntiva à postura epistêmica positiva.

Gramáticos e linguistas como Garcia (2000), Neves (2000), Luft (2002) e Azeredo (2008) não consideram a possibilidade de já que atuar como conjunção condicional, mas apenas causal. Por outro lado, Bechara (2003, p. 325) observa: " já, que tem valor originário temporal, ao unir-se ao que na fórmula já que, passa a uma interpretação causal ou condicional”.

Embora a maioria dos gramáticos trate já que exclusivamente como causal, e apresente as conjunções condicionais e causais como categorias mutuamente exclusivas, é forçoso reconhecer que a oração condicional frequentemente expressa uma causa (condicional) daquilo que a oração principal denota, de sorte que, quando a postura epistêmica é positiva, a oração introduzida por se estará indicando uma causa efetiva, sem deixar de ser condicional. Em nosso exemplo (1), ele ter feito o que fez é a causa de merecer punição.

Por outro lado, tem-se também de reconhecer que algumas orações introduzidas por já que podem ser parafraseadas com se, mas não todas. Quando admitem essa paráfrase, estarão indicando também uma condição suficiente, sem deixarem de ser causais. Por exemplo:

(5) Já que ele está atrasado, não poderá entrar.

(6) Se ele está atrasado, não poderá entrar.

Aqui, estar atrasado é causa de não poder entrar e, ao mesmo tempo, condição suficiente (realizada) para tal. Já no que diz respeito à postura epistêmica positiva nas condicionais, a maioria das gramáticas tradicionais da língua portuguesa é silente.

A justificativa da presente investigação está no interesse em compreender as condicionais como atos comunicativos, bem como em entender melhor seus aspectos cognitivos, ultrapassando uma visão puramente sintática das condicionais e superando limitações de seu tratamento pelas gramáticas tradicionais.

A primeira hipótese de nossa pesquisa é a de que, em contexto indefinido, uma condicional com indicativo no antecedente poderá ser interpretada como sendo de fato aceito ou incerto, e os sujeitos poderão preferir ou a paráfrase com já que ou com caso, respectivamente. 
A segunda hipótese é a de que, em contexto indutor de certeza, uma condicional com indicativo no antecedente será interpretada como sendo de fato aceito, e os sujeitos preferirão a paráfrase com já que.

Finalmente, como terceira hipótese, temos que, em contexto indutor de incerteza, uma condicional com indicativo ou futuro do subjuntivo no antecedente será interpretada como sendo de fato incerto, e os sujeitos preferirão a paráfrase com caso.

\section{Metodologia}

Um formulário incluindo 27 itens foi aplicado a 137 sujeitos, devendo eles em cada item escolher uma entre duas opções de paráfrase (uma com caso, a outra com já que). Foi solicitado que indicassem aquela que mais lhes parecia de acordo com a frase condicional do enunciado. Uma única resposta devia ser dada obrigatoriamente a cada item. Foi salientado que não havia resposta certa ou errada e que o objetivo era saber como naturalmente entendiam essas frases.

Nos primeiros 9 itens, a condicional era apresentada em contexto indefinido, ou seja, sem nenhuma outra frase indutora de uma interpretação particular. Sempre apresentava um tempo do indicativo no antecedente. Em seguida, as mesmas 9 frases eram apresentadas (com alterações na ordem) precedidas de uma frase indutora de uma interpretação de certeza ou de incerteza em relação à verdade do antecedente. Nos casos de contexto indutor de incerteza em que isso nos pareceu mais natural, o futuro do subjuntivo foi usado no antecedente. Apresentamos a seguir, a título de exemplo, os itens 1, 11 e 19:

1- Se ela é italiana, não precisa de passaporte para ir para a França.

( ) Caso ela seja italiana, não precisa de passaporte para ir para a França.

( ) Já que ela é italiana, não precisa de passaporte para ir para a França.

11- Ela é italiana. E se ela é italiana, não precisa de passaporte para ir para a França.

( ) Ela é italiana. E já que ela é italiana, não precisa de passaporte para ir para a França.

( ) Ela é italiana. E caso ela seja italiana, não precisa de passaporte para ir para a França. 
19- Talvez ela seja italiana. E se ela for italiana, não precisa de passaporte para ir para a França.

( ) Talvez ela seja italiana. E caso ela seja italiana, não precisa de passaporte para ir para a França.

( ) Talvez ela seja italiana. E já que ela é italiana, não precisa de passaporte para ir para a França.

A ordem em que as paráfrases eram apresentadas, em todos os contextos, era variada. Em estudo preliminar, não encontramos influência dessa ordem nos resultados obtidos. Os contextos indutores de incerteza incluíram a afirmação do antecedente precedido por Talvez (em 3 itens), Não sei se (em 3 itens), Às vezes, Ele quis saber se, e Ele pode... ou não. Os contextos indutores de certeza consistiam na afirmação prévia do antecedente, às vezes complementada por alguma razão ou circunstância que a justificasse.

Para a análise qualitativa, foram anotadas as perguntas e comentários feitos pelos entrevistados durante ou após o preenchimento do formulário, como: Posso não marcar nenhuma alternativa? ou Eu falaria das duas formas, posso marcar as duas opçôes? (Note-se que para essas duas perguntas a resposta era não). Ao término do formulário, fazíamos um inventário em que perguntávamos a respeito de algumas opçôes assinaladas pelos informantes. Mais uma vez, frisávamos que as escolhas não estavam erradas, mas que gostaríamos de saber um pouco mais sobre o pensamento expresso por algumas de suas opçóes. Essas perguntas se referiam às respostas que contrariavam o esperado, de acordo com nossas hipóteses. Por exemplo, nos itens 11 e 19 reproduzidos acima, esperávamos que a primeira opção fosse marcada. Quando a segunda era a escolhida, perguntávamos sobre as razões do entrevistado para tal.

Algumas pessoas mudavam sua resposta ao tentar explicar o porquê de suas escolhas e registrávamos em nosso inventário essa mudança e o porquê de ela ter ocorrido. Porém, os dados quantitativos de nossa pesquisa empírica se referem apenas às primeiras escolhas de nossos informantes. Optamos por registrar quantitativamente só as primeiras escolhas para não corrermos o risco de computar dados que pudessem ter sido influenciados pelos nossos questionamentos com o respondente.

Não pedíamos que os participantes de nosso estudo se identificassem no formulário e apenas registrávamos neste a idade, o sexo e a escolaridade. A entrevista, normalmente, durava cerca de 35 minutos, devido a não limitarmos 
nossa pesquisa a um simples preenchimento do formulário. Preliminarmente, buscávamos estabelecer um relacionamento amigável com o entrevistado, para tornar o resultado de nosso estudo o mais próximo do natural e depois o questionávamos, como descrito, sobre algumas de suas escolhas.

$\mathrm{O}$ fato de o formulário ser composto por 27 enunciados a serem respondidos muitas vezes ocasionou cansaço nos informantes. Isso fez, em vários casos, com que tivéssemos de dar uma pausa de cerca de dez minutos para que os informantes não os preenchessem de forma automática. Nesses casos, ultrapassamos os 35 minutos aproximados de nossa coleta de dados.

Dos 137 sujeitos entrevistados, 76 eram do sexo feminino e 61 do sexo masculino. 53 sujeitos estavam na faixa etária de 14-25 anos; 48 sujeitos estavam na faixa de 26-49 anos e 36 sujeitos tinham 50 anos ou mais. Em relação à escolaridade, 39 tinham o ensino fundamental completo ou incompleto; 63 tinham o ensino médio completo ou incompleto; e 35 tinham ensino superior completo ou incompleto. As entrevistas foram realizadas na cidade de Campos dos Goytacazes, RJ.

A análise estatística dos resultados foi feita usando o método do quiquadrado (COSTA NETO, 2005). Os dados também foram analisados qualitativamente, visando a uma melhor interpretação dos resultados obtidos.

\section{Resultados quantitativos}

As tabelas completas com os números de sujeitos que optaram por caso ou já que em cada item, distribuídos segundo as categorias demográficas pesquisadas, bem como as tabelas de contingência e os cálculos do qui-quadrado podem ser encontrados em Monken (2009).

A tabela a seguir apresenta os números de cada resposta nos três contextos e a porcentagem de respostas caso. Como cada item exigia uma única resposta caso ou já que, a porcentagem da outra resposta é sempre o complemento da porcentagem apresentada de uma resposta. No caso do contexto indefinido, por exemplo, houve $49 \%$ de respostas já que. 
TABELA 1

Frequência das respostas em função dos contextos (Monken, 2009).

\begin{tabular}{l|c|c|c}
\hline Respostas em & Respostas Caso & Respostas Já que & \% Respostas Caso \\
\hline Total & 1879 & 1820 & $51 \%$ \\
Contexto Indefinido & 634 & 599 & $51 \%$ \\
Contexto Indutor de Certeza & 368 & 865 & $30 \%$ \\
Contexto Indutor de Incerteza & 877 & 356 & $71 \%$ \\
\hline
\end{tabular}

Nos itens com contexto indefinido, houve 51\% de respostas caso. Nos itens com contexto indutor de certeza, houve $70 \%$ de respostas já que, e naqueles com contexto indutor de incerteza, $71 \%$ de respostas caso. A diferença observada entre os contextos de certeza e de incerteza foi significativa, pelo teste do quiquadrado, no nível de 0,001 .

\section{Resultados qualitativos e discussão geral dos resultados}

Nos itens com contexto indutor de incerteza, observamos uma predominância das respostas caso, e naqueles com contexto indutor de certeza, uma predominância das respostas já que, confirmando nossas hipóteses. A diferença entre as respostas nesses dois contextos mostrou-se altamente significativa (nível 0,001). Ainda assim, um número não desprezível de sujeitos deu a resposta já que no contexto de incerteza (29\%) e a resposta caso no contexto de certeza (30\%).

É pela análise qualitativa que podemos investigar o significado dessas repostas não previstas. Podemos atribuir algumas dessas respostas discrepantes simplesmente à falta de atenção, seja por cansaço, falta de interesse ou distração. Deve-se registrar também que vários sujeitos mudaram sua resposta no inventário, mas não computamos essa mudança em nossa estatística. A razão de não levarmos em conta a mudança foi que ela poderia ter sido motivada apenas pela própria pergunta que fizemos. $\mathrm{Na}$ avaliação qualitativa, entretanto, observamos que os sujeitos em geral davam razões para essa mudança, em função de seu entendimento das frases.

Outra observação, que nos surpreendeu, foi a tendência dos sujeitos a imaginarem criativamente contextos para as frases, independentemente dos contextos fornecidos. Esses contextos espontaneamente criados incluíam a atribuição de estados mentais ao enunciador, o que concorda com a observação 
de Ferrari (2011, p. 44): “Assume-se que o falante não apenas constrói mentalmente a realidade física externa, mas também os estados mentais de conhecimento, crença e intenção de seus interlocutores". No caso, o enunciador da condicional pesquisada ocupa, para o entrevistado, lugar equivalente ao de um interlocutor.

Muitas vezes, os contextos imaginados pelo entrevistado estavam em contradição ao contexto indutor de postura epistêmica fornecido. Talvez tenha colaborado para isso o fato de todas as frases terem sido apresentadas inicialmente sem qualquer contexto indutor, despertando assim a imaginação dos sujeitos. Em trabalho futuro, seria interessante utilizar os contextos indutores já na primeira apresentação da condicional, para evitar que o sujeito fique, depois, preso a um contexto criado por sua imaginação, o qual entra em conflito com o contexto indutor fornecido. No inventário, os sujeitos descreviam esses contextos criados por eles como justificativa para sua resposta, mesmo que estivessem em desacordo com a frase fornecida como contexto. Quando aceitavam ambas as possibilidades de paráfrase, é porque imaginavam contextos alternativos.

A produção de respostas discrepantes, bem como a aderência a contextos contraditórios aos fornecidos, que pudemos, em muitos casos, evidenciar, pode também ser vista como efeito de dificuldades de leitura, por parte de nossos informantes. Ao darem essas respostas, mostraram-se incapazes de se desfazerem de uma inferência incompatível com o contexto fornecido, evidenciando uma deficiência de ancoragem da interpretação da condicional no contexto fornecido.

Seja qual tenha sido o motivo das respostas discrepantes, a diferença, na direção esperada, entre os dois contextos, na maioria das respostas, com alta significância estatística, confirma nossas segunda e terceira hipóteses. Ou seja, a interpretação de fato incerto para o antecedente de uma condicional (postura epistêmica neutra) está relacionada à possibilidade de paráfrase com caso, e a de fato aceito (postura epistêmica positiva) à possibilidade de paráfrase com já que. Fica claro, por outro lado, que, para certo número de falantes, essas possibilidades de paráfrase não se mostram tão definidas e mutuamente exclusivas quanto esperávamos.

Nos itens com contexto indefinido, tivemos aproximadamente $50 \%$ de respostas para cada opção. Aceitando-se a correlação das respostas caso e já que com as interpretações de postura epistêmica neutra e positiva, respectivamente - correlação confirmada pelos resultados acima -, isso significa que, em contexto 
indefinido, as condicionais com antecedente no indicativo podem ser interpretadas como apresentando uma postura ou outra, ou seja, como exibindo factualidade aceita ou incerta (primeira hipótese).

\section{Conclusões}

Alguns consideram que uma postura epistêmica positiva do falante em relação ao conteúdo de uma frase condicional é incompatível com a própria formulação dessa frase. Consequentemente, ao ouvir uma frase condicional, o receptor possuidor da mesma competência linguística nunca deveria atribuir ao falante tal postura. Ao contrário, verificamos que a escolha de paráfrases com já que, em cerca de metade das frases sem contexto fornecido pesquisadas, e a escolha preferencial de tais paráfrases, nas frases com contexto indutor de certeza quanto à verdade do antecedente, indicam que a atribuição de postura epistêmica positiva (a única compatível com o uso de já que) é frequente na interpretação de frases condicionais.

Por outro lado, confirmamos que a possibilidade de paráfrase com o conector caso está correlacionada à postura epistêmica neutra (não foi pesquisada neste trabalho a postura epistêmica negativa). Em outro trabalho, examinaremos a influência das variáveis demográficas pesquisadas sobre a escolha de uma ou outra paráfrase.

Não encontramos confirmação para a afirmação de Gomes (2008), de que, para alguns dialetos da língua portuguesa, o uso do indicativo na prótase estaria preferencialmente associado, pelo menos em certos casos, a uma interpretação como condicional de fato aceito, ou seja, com atribuição de postura epistêmica positiva. Isso pode ter sido resultado do dialeto prevalente no local onde foi feita a pesquisa. De toda forma, esse ponto não foi especificamente estudado aqui e deveria ser objeto de novas pesquisas.

Em relação à metodologia empregada, o uso da parafraseabilidade diferencial mostrou-se um instrumento útil de investigação semântica. Além disso, o fornecimento de contextos mostrou-se também eficiente (embora nem sempre), para induzir uma determinada atribuição de postura epistêmica. Verificamos também a importância de associar à análise quantitativa uma investigação qualitativa dos resultados, para sua melhor interpretação. 


\section{Nota}

${ }^{1}$ Priscila Mattos Monken foi bolsista da FAPERJ durante a realização desta pesquisa. Agradecemos ao Prof. Nilson Sérgio Peres Stahl e a André Fernandes Meirelles pelo auxílio na análise estatística dos resultados.

\section{Referências}

AZEREDO, José Carlos de. Gramática Houaiss da Lingua Portuguesa. São Paulo: Publifolha, 2008.

BECHARA, Evanildo. Moderna gramática portuguesa. Rio de Janeiro: Lucerna, 2003.

COSTA, Ana Lúcia dos Prazeres. A variação entre formas de futuro do pretérito e de pretérito imperfeito no português informal no Rio de Janeiro. 1997. Dissertação (Mestrado) - Faculdade de Letras da UFRJ, Rio de Janeiro, 1997.

COSTA NETO, Pedro Luiz de Oliveira. Estatística. 2. ed. 2a reimpressão. São Paulo: Edgard Blucher, 2005.

DANCYGIER, Barbara; SWEETSER, Eve. Constructions with if, since and because: Causality, epistemic stance and clause order. In: COUPER-KUHLEN, E.; KORTMAN, B. (Org.). Cause, Condition, Concession, Contrast: Cognitive and Discourse Perspectives. Berlin: Mouton de Gruyter, 2000. p. 111-141.

DANCYGIER, Barbara; SWEETSER, Eve. Mental Spaces in Grammar: Conditional Constructions. Cambridge: Cambridge University Press, 2005.

FERRARI, Lilian. Introdução à linguistica cognitiva. São Paulo: Contexto, 2011.

FILLMORE, C. J. Epistemic stance and grammatical form in English conditional sentences. In: ZIOLKOWSKI, M.; NOSKE, M.; DEATON, K. (Org.). Papers from the 26th Regional Meeting of the Chicago Linguistic Society. Chicago: Chicago Linguistic Society, 1990. p. 137-162.

GARCIA, Othon M. Comunicação em prosa moderna: aprenda a escrever, aprendendo a pensar. 18 ed. Rio de Janeiro: Editora FGV, 2000.

GOMES, Gilberto. Three types of conditionals and their verb forms in English and Portuguese. Cognitive Linguistics, v. 19, n. 2, p. 219-240, 2008.

HARDER, P. Functional Semantics: A Theory of Meaning, Structure and Tense in English. Berlin: Mouton de Gruyter, 1996.

$\mathrm{KOCH}$, Ingedore Grunfeld Villaça. Argumentação e linguagem. 6. ed. São Paulo: Cortez, 2000. 
LEÃO, Ângela Vaz. O periodo hipotético iniciado por se. Tese de concurso. UFMG, Belo Horizonte, 1961.

LUFT, Celso Pedro. Moderna Gramática Brasileira. 14. ed. São Paulo: Globo, 2002. MONKEN, Priscila Mattos. Análise semântico-pragmática do conector se. 2009. Dissertação (Mestrado) - UENF, CCH, PGCL, Campos dos Goytacazes, 2009.

NEVES, Maria Helena de Moura. Gramática de usos do português. São Paulo: Editora UNESP, 2000.

SCHWENTER, Scott A. Pragmatics of Conditional Marking: Implicature, Scalarity and Exclusivity. New York and London: Garland, 1999.

TAYLOR, J. R. Conditionals and polarity. In: ATHANASIADOU, A.; DIRVEN, R. (Org.). On Conditionals Again. Amsterdam: Benjamins, 1997. 